\section{BALT PREV RESILIENCE THE BALTIC EVERYDAY ACCIDENT, DISASTER PREVENTION AND RESILIENCE PROJECT}

Rainar All. Swedish Civil Contingencies Agency

10.1136/injuryprev-2016-042156.807

Background There are too many injuries and fatalities, caused by everyday accidents, in the Baltic Sea Region (BSR) and EU.

The Balt Prev Resilience goal is to prevent and reduce the consequences of such accidents.

A key element in prevention and consequence reduction is improved learning from accidents and disasters, preferably already from minor everyday accidents.

Methods Balt Prev Resilience will enhance the learning and sharing of lessons. The project will introduce a process to achieve a common understanding of statistics, evaluation of experiences and sharing of evidence based knowledge and best practices.

Partners (forming a Project Steering Group):

- Swedish Civil Contingencies Agency (MSB), Project Coordinator

- National Institute for Health and Welfare, Injury Prevention Unit Finland (THL)

- Estonian Rescue Board, Estonia (ERB)

- Frederikssund-Halsnæs Fire \& Rescue Service, Denmark (FHFRS)

- Main School of Fire Service Warsaw, Poland (SGSP)

- Jelgava City Municipality, Latvia (JCM)

- Karlstad, University, Sweden (KaU)

Results The project dialogue will involve a wide and diversified group of relevant BSR emergency and crises actors and stakeholders. There will be three thematic UNEP APELL type seminars, prepared with studies on the themes collection of evidence based knowledge, assessment of information and data and learning, and finally awareness raising and building resilience.

The result will be a development of everyday accident and disaster prevention policies, in respect to both man-made and natural disasters, which is of significant importance at local, national, BSR and EU levels.

Conclusions Balt Prev Resilience will contribute significantly to implement the Priority Area Secure of the EU BSRS Action Plan and the EU HNS Guidelines to enhance protection from emergencies and accidents on land, in accordance with the UN Hyogo Framework for Action on Disaster Risk Reduction.

The project will be coordinated by a limited group of partners from BSR central and local government administration, research and training and civil protection services.

\section{MANAGEMENT OF INJURED AND DECEASED BUS PASSENGERS - ANALYSIS AND LESSONS LEARNT}

Vladimir Dobričanin, Nemanja Radojević, Ranko Lazović. Clinical Centre of Montenegro, Podgorica, Montenegro

10.1136/injuryprev-2016-042156.808

Background On $23^{\text {rd }}$ of June 2013, around 5 o'clock PM the severe traffic accidents on the road between Kolasin and Podgorica on the bridge called "GRLO". A traffic accident occurred when a bus from Romania broke through the railing of the bridge and landed in around $40 \mathrm{~m}$ the deep abyss. A total of 47 passengers were injured, of which the 15 were fatally injured on the site. A total of 32 passengers were transported to the Clinical Centre of Montenegro, which was the closest to the accident site. Three more injured died in Clinical Centre within the first 12 hours. A total of 27 passengers were treated. After four days all passengers were transported by special air medical transport to Romania.

Methods We analysed the complete management of accident by using the video material, personal experience, pictures, medical findings, the calculation of injury severity score based on the height of fall and SWOT analysis of the incident management performance.

Results The analysis shows many problems especially on the incident site beginning with site security issues pore site command management, lack of necessary fire and rescue equipment like high quality ropes, lack of necessary means for tagging the injured and deceased, poor medical transport equipment, deficiency in high quality medical triage, poor implementation of ITLS (International Trauma Life Support) standards.

Conclusions The medical emergency action plan regarding the traffic as a hazard is necessary for good quality management of such an incidents as a Mass Casualties Event. The education and good equipment can be crucial in the provision of adequate assistance and transport.

\section{Consumer Safety}

\section{Post Tue 2.22}

\section{ANALYSIS OF RECALL BEHAVIOUR IN JAPANESE MARKET}

${ }^{1}$ Yoshiki Mikami, ${ }^{2}$ Kun Zhang. ${ }^{1}$ Nagaoka University of Technology, Japan; ${ }^{2}$ International Research Fellow of the Japan Society for the Promotion of Science, Human Informatics Research Institute, National Institute of Advanced Industrial Science and Technology, Tokyo, Japan

\subsection{6/injuryprev-2016-042156.809}

Background More than thousand product recalls are announced every year in Japan. But no surveillance study has been made for several important questions. How much portion of defect products has been recalled? How long is the delay in the recall behaviour of manufacturers and importers in Japanese market?

Methods Two databases are employed for this study; (1) productrelated consumer injury database (IDB) provided by National Institute of Technology Evaluation (NITE), (2) product recall database (RDB) also provided by NITE. The reporting delay (time from date of accident to date of accident report to government), the recall decision delay (time from date of accident report to government to date of recall announcement) are calculated by matching two correspondent records in two databases. Product category, manufacturers/importers name, product model are used as a key to make correct matching. Comparison of two aspects of delays are made by product category, by manufacturer, by the country of origin, by the causes of accident, by the year of accident, etc.

Results Our preliminary investigations on the case of home electronic appliances shows that only less than half of accident reports found their corresponding recalls. The report delay is often longer than one user. The decision delay is also far longer than our expectation, often longer than one year. Also we found that many records are lacking key information such as product model (number). 
Conclusions This study suggests us that monitoring of recall behaviour would be an efficient and practical tool for compliance assessment of players in the market. It can tell us which manufacturers are possibly very reluctant or lazy in recall actions. Also this study suggest us some improvement is needed for accident database and recall database.

\section{EPIDEMIOLOGICAL CHARACTERISTICS OF PRODUCT HARM CASES IN 32 HOSPITALS IN 11 AREAS IN CHINA, 2012-2014}

Ye Pengpeng, Er Yuliang, Wang Yuan, Deng Xiao, Duan Leilei. National Centre for Chronic and Noncommunicable Disease Control and Prevention, Chinese Centre for Disease Control and Prevention, China

\subsection{6/injuryprev-2016-042156.810}

Background To understand the epidemiological characteristics of product harm cases in 32 hospitals in 11 areas in China from 2012 to 2014 and provide the basic data to support for productspecific survey, product harm early warning and the assessment of product safety.

Methods The descriptive epidemiologic analysis was conducted by using the surveillance data of product harm collected from 32 hospitals in 11 areas in China during 2012-2014.

Results A total of 208772 product harm cases were reported in the 32 hospitals during 2012-2014, accounting for $19.50 \%$ of total harm cases during the same period. A total of 222401 cases (times) of product harm were reported. For all the product harms, the top five products causing harms were transportation equipment except motor vehicle (36.55\%), motor vehicle (21.50\%), other products (20.84\%), furniture (7.21\%) and food, medicine and related products $(5.18 \%)$. Both the case number and times of product harm were higher in males than in females. Males aged 25-44 years might be at greater risk for product harm. Most product harms, i.e. bruise, were caused by blunt force on heads.

Conclusions The epidemiologic characteristics of product harm varied with products. It is necessary to take targeted intervention measures to prevent product harm in China.

\section{THE USE OF INJURY DATA AS DRIVER FOR EFFECTIVE PRODUCT SAFETY STANDARDS}

Tania Vandenberghe. ANEC, the European Consumer Voice in Standardisation, Brussels

\subsection{6/injuryprev-2016-042156.811}

Background For consumers, standards are important. When they are properly developed and applied, they can make our lives easier, the products we buy safer, and help prevent injuries and accidents. In order to properly develop standards leading to safer products, it is very important to have accident and injury statistics at our disposal.

Methods One powerful aspect of ANEC's pan-European network of experts is that it has the ability to spot emerging trends, as there is no pan-European data system that allows this to happen. Thanks to the availability of accident data from some countries, ANEC asked the European Standardisation organisation CEN for standards to be set up for cords and drawstrings on children's clothing, moveable goals and 'nappy sacks', and asked for improving the standards for cigarette lighters and window blinds.
Results ANEC was successful in asking for standards to be set up for cords and drawstrings on children's clothing, for moveable goals, and in improving the safety of cigarette lighters and window blinds through standardisation. Unfortunately, only a few countries within the EU systematically collect accident and injury data. This lack of data is often used by some stakeholders as an excuse not to improve standards. As a result, ANEC has not been able for the standard for small off-road motorbikes to address child safety aspects, nor for the standard for the safety of children's clothing to address the risk of hoods. The request from ANEC to set up a standard for 'nappy sacks' was not followed up, as data on fatal accidents was only available from one country.

Conclusions Lack of EU-funded accident \& injury data system makes it difficult to assess where legislative, standardisation, market surveillance, and/or awareness raising actions are needed and to assess the success of measures/actions taken. Therefore, there is an urgent need for a pan-European accident $\&$ injury data system, funded by the European Commission.

\section{REVISION OF THE SAFETY STANDARDS FOR A BABY CHAIR UTILISING INJURY DATA}

\begin{abstract}
1,2,3 Tatsuhiro Yamanaka, 2,3Yoshifumi Nishida, 2,3Mikiko Oono, 2,3 Koji Kitamura, ${ }^{4}$ Takeshi Sato, ${ }^{4}$ Shuichi Kurokawa. 'Ryokuen Children's Clinic, Japan; ${ }^{2}$ National Institute of Advanced Industrial Science and Technology, Japan; ${ }^{3}$ Safe Kids Japan, Japan; ${ }^{4}$ Consumer Product Safety Association, Japan
\end{abstract}

\subsection{6/injuryprev-2016-042156.812}

Background Since the SG (Safe Goods) Standards for a baby chair was enacted by Consumer Product Safety Association in 1981, no revision has been made for 30 years. During these years, new types of products to which the SG Standards did not apply became available, serious injuries related to old type chairs were reported, and other issues came up related to a baby chair. Then it is necessary to revise the standard as soon as possible. The purpose of this study is to analyse baby chair-related injury data and revise the safety quality requirements.

Methods We analysed 99 baby chair-related injuries that required ambulance transport to identify a specific body part being caught and a part of a chair that caused injury in cooperation with Tokyo Fire Department.

Results The body parts caught in a baby pipe chair, a metal-pipeframe low chair which is usually cheap with simple design, were: fingers (31 cases), feet (18 cases), head/neck (10 cases), toes (8 cases), and ankles (4 cases). Among 99 cases, 10 cases occurred in 0 year old, 28 cases in 1 year old, 26 cases in 2 years old, 13 cases in 3 years old, 14 cases in 4 years old, and 5 cases in 5 years old. When a child's body size is within 25 percentiles, his or her head is bigger than a trunk. Thus, in order to check the entrapment and strangulation hazard, we developed a probe $(95 \times 140 \mathrm{~mm})$ which mimics a trunk of a child body utilising data on a body trunk jig dimension suited for Japanese infants of National Institute of Technology and Evaluation. The revised standard requires that we must use the developed probe to check injury risk.

Conclusions As a result of injury data analysis, we found that children under 2 were more prone to a baby chair-related injury and understood how injury occurred in details. When a child's head is caught in clearance between the parts of a baby chair, it might cause suffocation. We developed a trunk probe to check injury risk for a pipe chair for ages 7-36 months and established a new safety standard requirement. From this standard revision 